\title{
Cerebral Venous Thrombosis Due To Neurobrucellosis: A Case Report
}

Salma Sakka ${ }^{{ }^{*}}$, Nouha Bouzidi ${ }^{1}$, Ines Feki ${ }^{2}$, Wafa Abbes ${ }^{2}$, Mariem Dammak ${ }^{1}$, Masmoudi Jaweher $^{2}$ and Chokri Mhiri ${ }^{1}$

${ }^{1}$ Department of Neurology, Habib Bourguiba Hospital, Sfax, Tunisia

${ }^{2}$ Department of psychiatric disease, Hedi chaker Hospital, Sfax, Tunisia

*Corresponding author: Salma Sakka, Department of Neurology, Habib Bourguiba Hospital, Sfax, Tunisia, Tel: +21674241511; E-mail: salma.sakkacharfi@gmail.com Received date: May 26, 2016; Accepted date: August 24, 2016; Published date: August 31, 2016

Copyright: (C) 2016 Sakka S, et al. This is an open-access article distributed under the terms of the Creative Commons Attribution License, which permits unrestricted use, distribution, and reproduction in any medium, provided the original author and source are credited.

\begin{abstract}
The involvement of the central peripheral nervous system (CNS) in brucellosis is rare. Cerebral venous thrombosis (CVT) is an exceptional complication. Only three cases were reported in literature.

We reported the case of 52 year old Tunisian women that had psychiatric disorders since 2 years without treatment. She had brucellosis diagnosis by positive standard agglutination test and she was treated by doxycyline. She was admitted with the history of fever, headache, vomiting neck stiffness and confusion. Neurological examination found disorientation and meningeal signs. Brain Magnetic resonance imaging revealed a right lateral transverse sinus thrombosis. Blood culture grew Brucella melitensis and the brucella antibody titre was positive. Cerebrospinal fluid (CSF) analysis revealed lymphocytic meningitis. She was treated by anticoagulant (LMWH) and association of 2 antibiotics (doxycyline and rifampicin). During follow-up, we remarked a significant and rapid clinical improvement.
\end{abstract}

Keywords Neurobrucellosis; Cerebral venous thrombosis; Lateral transverse sinus

\section{Introduction}

Brucellosis is a rare multisystemic zoonotic infection caused by coccobacilli gram negative bacteria "brucella". It is specially observed in endemic countries particularly in rural areas. Myalgia, arthralgia, fiver and asthenia are the main clinical manifestations [1]. Neurological complications are rare reported in $3-5 \%$ of cases and affected both central and peripheral nervous system $[2,3]$

The most frequent neurological manifestations are meningitis and meningo-encephalitis [4]. The other major complications in neurobrucellosis are neuropsychiatric symptoms (agitation, depression, confusion...), sleep disorder, epilepsy, headache, intracranial hypertension, cranial nerve $(\mathrm{CN})$ involvement, and polyradiculoneuritis [4-7]. However, thrombotic or hemorrhagic vascular complications are exceptional. Only few cases of cerebral venous thrombosis (CVT) due to neurobrucellosis were reported in literature [8-10].

\section{Case Report}

A 52 year old woman is brought by her family for behavioral disorder. In fact, she was a farm hand and presented 2 years ago with the symptoms of mood fluctuation (episodes of agitation and depression), hallucination, memory loss and episode of confusion. She was not treated for these symptoms and did not take any medication. She has not been exposed to potentially toxic substances. She drinks raw goat's milk.

One month ago, she complained from headache, vomiting, attacks of fever and three day before admission to hospital she presented neck stiffness and attention deficit.
At physical examination, she was febrile (temperature: $39^{\circ} \mathrm{C}$ ), meningeal signs were evident with neck stiffness and she was disoriented. Otolaryngological examination was normal; there was no sign of otitis, mastoiditis or buccal abscess. Pulmonary auscultation was unremarkable. Brain magnetic resonance imaging (MRI) confirmed right lateral transverse sinus thromboses as well as a thrombus in the right internal jugular vein without any change in brain parenchyma. There is no sign of subdural empyema or hydrocephalus (Figure 1).

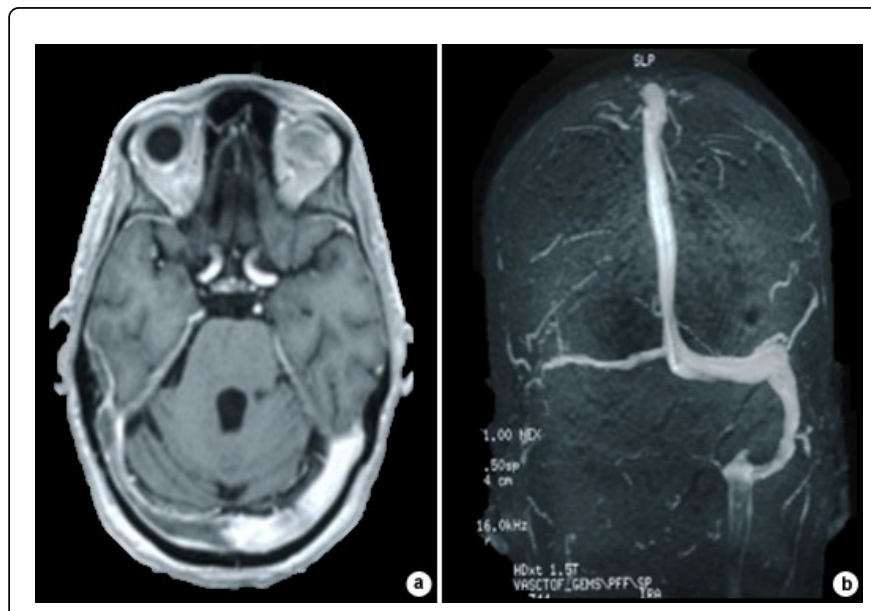

Figure 1: T1 weighted brain MRI after gadolinium injection (a) and MR angiography (b) showing right lateral sinus thrombosis and enhancement of the meninges.

The laboratory work-up demonstrates leucopenia in blood cell count $\left(3300 / \mathrm{m}^{3}\right)$, ESR was accelerated (60 first hours) and C-reactive protein level was increased $(117 \mathrm{mg} / \mathrm{l})$ suggesting inflammatory 
syndrome. Cerebrospinal tap demonstrated a marked increase in the cerebrospinal pressure with an opening pressure of $350 \mathrm{~mm} \mathrm{H}_{2} \mathrm{O}$. Cerebrospinal fluid (CSF) analysis revealed: 20 white blood cells $/ \mathrm{mm}^{3}$, glucose $35 \mathrm{mg} / \mathrm{dl}$, protein $1.05 \mathrm{~g} / \mathrm{l}$. PCR of CSF did not find viral genome including herpes Herpes Simplex Virus (HSV), Ebstein-Barr virus (EBV), cytomegalovirus (CMV) and herpes (HSV). Immunological tests such as antinuclear, anticardiolipin and antiphospholipid antibodies were normal. Levels of $\mathrm{C}$ protein, $\mathrm{S}$ protein and antithrombin III were within normal range. There was no resistance to activated $\mathrm{C}$ protein.

Wright agglutination test for brucellosis in serum was positive at a very high titer (1/1280). Blood culture during a fever attack disclosed Brucella.

Based on these results, diagnosis of brucellosis was confirmed. The patient was started on an oral combination of 3 antibiotics; rifampin, doxycycline and Sulfamethoxazole/trimethoprim; and anticoagulation. During follow-up, we remarked a significant and rapid clinical improvement. Fever, headache and meningeal signs disappeared within few days; however psychiatric disorders dissipate more slowly. Treatment combining anticoagulant and 2 antibiotics was extended for 6 months.

\section{Discussion}

Brucellosis remains a major public health problem in many countries such as in Tunisia. This bacterium can involve both central and peripheral nervous system. Neurological complications are rare but polymorph making the diagnosis difficult particularly when the infection is unknown. Diagnosis of neurobrucellosis required compatible clinical history with CSF showing pleocytosis $\left(>20 / \mathrm{mm}^{3}\right)$, elevated protein content $(>45 \mathrm{mg} / \mathrm{dL})$, low CSF/plasma glucose rate $(<0.50)$; and isolation of brucella from blood or CSF, or serology of brucellosis positive in CSF [11]. Our patient had evident clinical meningeal syndrome with a clinical history of brucellosis, isolation of brucella from blood associated with lymphocytic meningitis in the CSF.

Psychiatric disorders such as cognitive impairment, depression, amnesia, psychosis agitation, nightmares, personality disorders, are fairly common complications of neurobrucellosis with or without neurological involvement and could be indicative of the disease especially when it appears at a late age [5].

Vascular complications of brucellosis are rare and it affected preferentially arteries than veins $[12,13]$. Certain vascular complications have been reported in Tunisia such as deep vein thrombosis (DVT), however, cerebral venous thrombosis (CVT) has not been yet described in this endemic countries [12]. CVT as a manifestation of neurobrucellosis is extremely rare. In 1999, Zaidan et al. [8] reported the first case of brucellosis complicated with cerebral venous thrombosis in Arabia Saudi. In 2013, Faraji et al. described uncontrolled seizures resulting from CVT complicating neurobrucellosis [9].

Septic lateral sinus thrombosis is usually caused by local or regional infections (otitis, mastoiditis...). Many bacteria were described such as Staphylococcus, Enterobacteriaceae, Proteus, Pseudomonas and others species. Brucella melitensis has not been reported in septic lateral sinus thrombosis [14]. Three mechanisms may explain the vein thrombosis: compressive, inflammatory process or hypercoagulable state secondary to the release of toxin or antigen by brucella [12]. In our case, levels of physiological coagulation inhibitors were normal and there was no compressive factor at MRI. CVT seems to be related to the inflammation of the dura constituting the wall of the lateral sinus.

There is no clear guideline for the treatment of brucellosis; however all the authors agree that combination of 2 or 3 antibiotics is mandatory. Some authors recommend the following antibiotics: doxycycline, rifampicin, trimethoprim-sulfamethoxazole, streptomycin, and/or ceftriaxone for a period of 4 to 9 months [4]. Usefulness of anticoagulation therapy remains controversial, some authors think that it prevents the extension of thrombosis and recommend its use in all cases of CVT regardless to its origin septic or aseptic [14].

\section{Conclusion}

Neurological complications of brucellosis are rare but polymorph and nonspecific, they could be severe and life threatening. Psychiatric symptoms and CVT are rarely observed. It is important to think about brucellosis in endemic areas. Blood tests should be performed rapidly. Early diagnosis and specific treatment are the unique guarantee to have good prognosis and better outcomes.

\section{References}

1. Young EJ (2005) Brucella species. In: Mandell GL, Bennett JE and Dolin R Eds, Principles and Practice of Infectious Diseases (6thedn), Churchill Livingstone, Philadelphia pp. 2669-2762.

2. McLean DR, Russell N, Khan MY (1992) Neurobrucellosis: Clinical and therapeutic features. Clin Infect Dis 15: 582-590.

3. Bouza E, García de la Torre M, Parras F, Guerrero A, Rodríguez-Créixems M, et al. (1987) Brucellar meningitis. Rev Infect Dis 9: 810-822.

4. Jiao LD, Chu CB, Kumar CJ, Cui J, Wang XL, et al. (2015) Clinical and laboratory findings of non-acute neurobrucellosis. Chin Med J (Engl) 128: 1831-1833.

5. Shehata GA, Abdel-Baky L, Rashed H, Elamin H (2010) Neuropsychiatric evaluation of patients with brucellosis. J Neurovirol 16: 48-55.

6. Eren S, Bayam G, Ergönül O, Çelikbaş A, Pazvantoğlu O, et al. (2006) Cognitive and emotional changes in neurobrucellosis. J Infect 53: 184-189.

7. Bodur H, Erbay A, Akinci E, Colpan A, Cevik MA, et al. (2002) Neurobrucellosis in an endemic area of brucellosis. Scand J Infect Dis 35: 94-97.

8. Zaidan R, Al Tahan AR (1999) Cerebral venous thrombosis: A new manifestation of neurobrucellosis. Clin Infect Dis 28: 399-400.

9. Faraji F, Didgar F, Talaie-Zanjani A and Mohammadbeigi A (2013) Uncontrolled seizures resulting from cerebral venous sinus thrombosis complicating neurobrucellosis. J Neurosci Rural Pract 4: 313-316.

10. Lima JI, Canelas CF, Veiga AS, Carvalho DM (2016) Neurobrucellosis and venous sinus thrombosis: An uncommon association. Rev Soc Bras Med Trop 49: 383-385.

11. Karsen H, Tekin Koruk S, Duygu F, Yapici K, Kati M (2012) Review of 17 cases of neurobrucellosis: Clinical manifestations, diagnosis and management. Arch Iran Med 15: 491-494.

12. Koubaa M, Frigui M, Cherif Y, Jallouli M, Kaddour N, et al. (2013) Deep vein thrombosis associated with acute brucellosis: A case report and review of the literature. Korean J Intern Med 28: 628-630.

13. Davoudi AR, Tayebi A, Najafi N, Kasiri E (2014) Deep vein thrombosis as a rare complication of brucellosis. Caspian J Intern Med 5: 127-129.

14. Viswanatha B, Thriveni CN, Naseeruddin K (2014) Nonseptic and septic lateral sinus thrombosis: A review. Indian J Otolaryngol Head Neck Surg 66: $10-15$. 